\title{
Analysis of alternative ventilation strategies for existing multi- family buildings using CONTAM simulation software
}

\author{
Xinxiu Tian ${ }^{1}$, Jamie Fine ${ }^{1}$, and Marianne Touchie ${ }^{1,2}$ \\ ${ }^{1}$ Department of Mechanical and Industrial Engineering, University of Toronto, Toronto, Canada \\ ${ }^{2}$ Department of Civil and Mineral Engineering, University of Toronto, Toronto, Canada
}

\begin{abstract}
In many existing high-rise multi-family buildings, a pressurized corridor ventilation system is used to meet outdoor air ventilation requirements. However, this system often has poor performance, leading to under- or over- ventilation in different parts of a building. This study examines three ventilation strategies including: the base case, which is a traditional pressurized corridor ventilation system, a directto-suite ducted ventilation system, and a suite-based HRV ventilation system. A building model was constructed in CONTAM using features of a typical post-war multi-family building in Toronto, Canada. All three strategies were simulated using CONTAM under both summer and winter conditions. The resulting outdoor airflow delivery rates to the suites and corridor pressure differentials were compared to assess the effectiveness of each strategy. The results show that the suite-based HRV strategy is able to provide adequate ventilation airflow to individual suites in both summer and winter. In the traditional pressurized corridor system and the direct-to-suite ducting system, the airflows delivered to the suites located at the top of the building are higher than those delivered to the suites located at the bottom of the building. This uneven airflow distribution is more pronounced in winter when stack effect impacts the ventilation system more significantly.
\end{abstract}

\section{Introduction}

Indoor air quality (IAQ) plays a crucial role with regard to public health. In the epidemiological literature, there is robust evidence for an association between IAQ and lung cancer, allergies, and other hypersensitivity reactions [1]. Field and laboratory experiments have also demonstrated that poor indoor air quality can reduce occupant productivity and comfort level [2]. These findings hold true especially given the fact that humans are largely an indoor species. The average Canadian, for instance, has been found to spend $95 \%$ of their time indoors, $66 \%$ of which they spend at home [3]. In order to provide acceptable IAQ in residential homes, ASHRAE Standard 62.2 prescribes ventilation air requirements in dwelling units based on the floor area and the number of bedrooms [4].

To achieve these ventilation requirements, many high-rise multi-family (MF) buildings use pressurized corridor ventilation systems $[5,6]$. In North America in particular, this type of ventilation system is common in both existing and newly constructed MF buildings. In theory, this positive pressurization of the corridor relative to the surrounding suites forces air through gaps around suite entry doors, which are sized to allow the flow of ventilation air into the suites.
However, in high-rise MF buildings, central ventilation systems often exhibit poor performance. Previous studies have demonstrated that some areas of the building are over-ventilated, resulting in excessive energy consumption, while other areas of the building are under-ventilated, leading to poor indoor air quality [6]. These issues are often caused by uncontrolled air leakage between floors and between suites, the dynamics of wind and stack effect, and occupant behaviors such as window operation $[5,6,7,8,9,10]$. The presence of multistory vertical penetrations, such as elevator shafts, stairwells, and ventilation ducts, also exacerbate these issues associated with centralized ventilation systems [6].

Another issue impacting the effectiveness of central ventilation systems is inter-zonal air leakage caused by unbalanced mechanical systems. For example, many MF buildings have intermittent bathroom or kitchen exhausts. When an exhaust fan is turned on in only one suite, the suite is depressurized relative to its adjacent suites, which can promote the migration of odors and contaminants between suites [10].

This study examines two proposed retrofit approaches to improve the distribution of ventilation air to suites compared with the central pressurized corridor ventilation strategy. The first, which is currently being investigated by a social housing provider in Canada, involves ducting ventilation air directly from existing corridor air terminals into suites. The second is based on 
systems currently implemented in many new high-rise MF buildings in Toronto, Canada, where suites are outfit with individual Heat Recovery Ventilators (HRV). Both retrofit strategies still require positive corridor pressurization to prevent the migration of odors and contaminants between suites, but with a much lower air flow rate than the base case because the air delivered to the corridor is no longer intended for the suites. This paper continues with an overview of ventilation standards, strategies, and previous studies.

\section{Background}

This section begins with a presentation of the regulations and standards that govern residential ventilation. Then, a summary of the common centralized and decentralized ventilation strategies in high-rise MF buildings and an overview of studies that focus on comparing different ventilation strategies in MF buildings are presented.

\subsection{ASHRAE ventilation standards}

To provide acceptable IAQ in residential buildings, ASHRAE Standard 62.2 [4] "defines the roles of and minimum requirements for mechanical and natural ventilation systems and the building envelope". It provides recommendations for the total ventilation rate in a dwelling unit based on the floor area and the number of bedrooms. It also prescribes the local ventilation exhaust airflow rates for bathrooms and enclosed or nonenclosed kitchens. The airflow requirements set by ASHRAE Standard 62.2 [4] were used to determine the design airflow of individual suites in this paper.

\subsection{Centralized ventilation in high-rise MF buildings}

Many older high-rise MF buildings (and even some brand new MF buildings) use centralized ventilation strategies, which typically rely on the pressurization of common corridors to distribute ventilation air into individual suites $[5,6,7,8,9]$. This system uses a centralized make-up air unit (MAU) to supply fresh air to the building continuously, or on a user-specified schedule. When outdoor air is drawn in by the MAU, it is usually filtered and/or thermally conditioned according to a desired temperature set-point. Then, the conditioned air is distributed to each floor through large vertical ducts and air terminals located on each floor. This flow of air positively pressurizes the corridor relative to the surrounding suites. As a result, it can also be used to prevent the inter-suite distribution of odors and contaminants.

In newer high-rise MF buildings, ventilation air is often delivered directly to individual suites through direct-to-suite ductwork connected to the main vertical duct to improve ventilation air distribution to the suites. However, the cost of this approach is higher than corridor pressurization alone and extra space is required for direct-to-suite ductwork [11].
The performance of these two centralized ventilation strategies is affected by stack effect and wind. In addition, some occupants feel frustrated that they cannot control ventilation in their suite with the changing indoor environmental conditions in their homes [12]. Above all, since central ventilation strategies include a high level of interconnectivity between individual suites and common areas, smoke and fire control are significantly compromised [12].

\subsection{Decentralized ventilation in high-rise MF buildings}

Decentralized ventilation is currently implemented in many new high-rise MF buildings. This approach usually relies on a suite-based heat recovery ventilator (HRV) to deliver outdoor air to the suite and exhaust stale air directly to the exterior, in a balanced fashion [12]. Compared to a centralized system, this decentralized approach can provide residents with greater control of the amount of outdoor air delivered to their suite, which can improve occupant comfort and satisfaction. If linked to occupancy-based controls, this type of system can also be used to reduce energy use when the suite is unoccupied [11]. In high-rise MF buildings, decentralized ventilation is less susceptible to wind and stack effects since the system does not have to balance the ventilation airflow throughout the whole building [12]. However, decentralized ventilation strategies tend to have higher initial capital costs and suite-based equipment maintenance can present challenges and increase operating costs [12].

\subsection{Previous Studies on ventilation strategies in MF buildings}

There have been numerous studies on centralized $[5,6,7$, $8,9]$ and decentralized [13, 14] MF ventilation system performance, but none of these studies have directly compared the performance of two different strategies in the same high-rise building. However, two studies have carried out this comparison in low-rise MF buildings, which are discussed here.

Saari et al. (2000) [15] conducted an in-situ comparison of four low-rise multi-story apartment buildings and HVAC systems. Using results from a questionnaire, and monitoring of $\mathrm{CO}_{2}$ and relative humidity, they found that the air quality was 'good' in three of the buildings where both mechanical supply and exhaust were installed. However, the one building that had a centralized exhaust-only system experienced inadequate ventilation and high $\mathrm{CO}_{2}$ concentrations. While their study only had a small sample size, their findings suggest that using mechanical supply and exhaust together is important for achieving good indoor air quality. They also found that the total electricity consumption of fans was twice as high in centralized ventilation units as compared to apartment-based units, indicating that a decentralized ventilation system also has energy-saving potential over a centralized ventilation system. 
Koiv et al. (2015) [16] studied different ventilation strategies using a simulation approach. Their work included simulations of centralized systems, apartmentand room-based systems, and systems with heat recovery in low-rise apartment buildings in cold climates. They found that in small, two-room apartments $\left(50 \mathrm{~m}^{2}\right)$, roombased ventilation with an HRV is the most suitable solution because it exhibited the largest energy-saving potential. On the other hand, in large apartments, they found that apartment-based air handling units are both technically and economically optimal. They also found that in two- to three- story low-rise MF buildings, a central balanced ventilation strategy can achieve both good air quality and economic characteristics.

Given that air flow in low-rise buildings is less impacted by wind and stack, the findings from these low-rise studies cannot be directly applied in a high-rise context. Therefore, there is a need to compare the ventilation efficacy of centralized and decentralized ventilation strategies in high-rise MF buildings.

\section{Methodology}

To assess the performance of the two proposed retrofit strategies compared to the base case, calibrated airflow models were developed using CONTAM for an archetypal building. This section describes the subject building, the modeling approach and calibration procedure, and the field data collection method used to support the modeling.

\subsection{Building description}

The subject building, constructed in 1970, exhibits many of the typical design features and construction approaches used for post-war MF buildings. The building has 24 floors with double-loaded corridors of 12 units from the $3^{\text {rd }}$ floor to the $24^{\text {th }}$ floor. The first-floor suites have been converted to offices, a daycare center, and maintenance rooms. The second floor contains a laundry room that spans several suites on one side of the building. The building has two underground levels, both of which are used for parking. This building uses the traditional pressurized corridor ventilation system with two roof-top MAUs, combined with roof-top exhaust fans that remove air from the in-suite bathrooms continuously. There are no kitchen exhaust fans.

\subsection{Modeling approach}

For this study, we used CONTAM version 3.2. Developed by the National Institute of Standards and Technology (NIST), this program is a multi-zone ventilation analysis program designed to determine airflows, including infiltration, exfiltration, inter-zonal air leakage between suites, and pressure differences in buildings [17].

A base case model (pressurized corridor ventilation system) was built in CONTAM for the subject building. Building airtightness characteristics for the CONTAM model include data from airtightness tests conducted at the subject building, in a laboratory, and supplemented by data collected from the literature. The model inputs from the field and lab tests are presented in Table 1, along with the corresponding CONTAM input information. The model inputs from the literature are presented in Table 2 and were all modeled as one-way flow using the power law. Inputs for all mechanical systems in the base model were determined from the mechanical drawings of the subject building and are summarized in Table 3. CONTAM airflow simulations were performed under summer and winter weather conditions. Wind effects and the impacts of window operation are not included in the scope of this study.

Table 1. Measured inputs for the CONTAM model.

\begin{tabular}{|c|c|c|c|}
\hline $\begin{array}{l}\text { Building } \\
\text { Component }\end{array}$ & $\begin{array}{l}\text { CONTAM } \\
\text { Input }\end{array}$ & $\begin{array}{l}\text { Input } \\
\text { Description }\end{array}$ & Source \\
\hline $\begin{array}{l}\text { Suite } \\
\text { Windows }\end{array}$ & $\begin{array}{l}\mathrm{C}=0.0005 \\
\mathrm{~m}^{3} / \mathrm{s} / \mathrm{Pa}^{\mathrm{n}} \\
\mathrm{n}=0.722\end{array}$ & \multirow{3}{*}{$\begin{array}{l}\text { One-way flow } \\
\text { using power } \\
\text { law }\end{array}$} & \multirow{2}{*}{$\begin{array}{l}\text { Field } \\
\text { airtightness } \\
\text { test }\end{array}$} \\
\hline Balcony Door & $\begin{array}{l}\mathrm{C}=0.0002 \\
\mathrm{~m}^{3} / \mathrm{s} / \mathrm{Pa}^{\mathrm{n}} \\
\mathrm{n}=0.679\end{array}$ & & \\
\hline $\begin{array}{l}\text { Suite } \\
\text { Entrance } \\
\text { Door (tight) }\end{array}$ & $\begin{array}{l}\mathrm{C}=0.0029 \\
\mathrm{~m}^{3} / \mathrm{s} / \mathrm{Pa}^{\mathrm{n}} \\
\mathrm{n}=0.575\end{array}$ & & $\begin{array}{l}\text { Laboratory } \\
\text { airtightness } \\
\text { test }\end{array}$ \\
\hline Garage Door & - & $\begin{array}{l}\text { Crack } \\
\text { description }\end{array}$ & $\begin{array}{l}\text { Best } \\
\text { estimate } \\
\text { from field } \\
\text { observation }\end{array}$ \\
\hline
\end{tabular}

Table 2. Theoretical inputs for the CONTAM model.

\begin{tabular}{|l|l|l|}
\hline $\begin{array}{l}\text { Building } \\
\text { Component }\end{array}$ & $\begin{array}{l}\text { CONTAM } \\
\text { Input }\end{array}$ & Source \\
\hline $\begin{array}{l}\text { Suite Entrance } \\
\text { Door (loose) }\end{array}$ & $\begin{array}{l}\mathrm{C}= \\
0.00747 \\
\mathrm{~m}^{3} / \mathrm{s} / \mathrm{Pa}^{\mathrm{n}} \\
\mathrm{n}=0.6\end{array}$ & $\begin{array}{l}\text { Ricketts (2014) [7] } \\
\text { Note: C and } \mathrm{n} \text { values are } \\
\text { average values of the nine } \\
\text { tested doors in a MF building. }\end{array}$ \\
\hline $\begin{array}{l}\text { Envelope Wall } \\
\text { (without }\end{array}$ & $\begin{array}{l}\mathrm{C}=0.082 \\
\mathrm{Lps} / \mathrm{Pa}^{\mathrm{n}} \mathrm{m}^{2} \\
\text { windows and } \\
\text { doors) }\end{array}$ & $\begin{array}{l}\text { Orme et al. (1998) [18] } \\
\text { Leakage characteristic of } \\
\text { concrete block (lower } \\
\text { quartile) }\end{array}$ \\
\hline $\begin{array}{l}\text { Envelope Wall } \\
\text { (entire } \\
\text { envelope) }\end{array}$ & $\begin{array}{l}2.0 \mathrm{Lps} / \mathrm{m}^{2} \\
\mathrm{at} 75 \mathrm{~Pa}\end{array}$ & $\begin{array}{l}\text { ASHRAE Standard 90.1 } \\
\text { (2016) [19] }\end{array}$ \\
\hline Suite Wall & $\begin{array}{l}\mathrm{C}=0.021 \\
\mathrm{Lps} / \mathrm{Pa}^{\mathrm{n}} \mathrm{m}^{2}\end{array}$ & $\begin{array}{l}\text { Orme et al. (1998) [18] } \\
\text { Leakage characteristic of } \\
\text { concrete block (plastered, } \\
\text { internal) }\end{array}$ \\
\hline $\begin{array}{l}\text { Ceiling/Floor } \\
\text { Slab }\end{array}$ & $\begin{array}{l}\mathrm{C}=0.034 \\
\mathrm{Lps} / \mathrm{Pa}^{\mathrm{n}} \mathrm{m}^{2} \\
\mathrm{n}=0.65\end{array}$ & $\begin{array}{l}\text { Shaw et al. (1991) [20] } \\
\text { Average airtightness value of } \\
\text { floor/ceiling separation in } \\
\text { individual apartments. }\end{array}$ \\
\hline $\begin{array}{l}\text { Stairwell Door } \\
\mathrm{C}=0.55\end{array}$ & $\begin{array}{l}\text { Ricketts (2014) [7] } \\
\text { Note: C and } \mathrm{n} \text { values are } \\
\mathrm{m}^{3} / \mathrm{s} / \mathrm{Pa}^{\mathrm{n}} \\
\mathrm{n}=02045 \\
\mathrm{C}=0.0276 \\
\mathrm{~m}^{3} / \mathrm{s} / \mathrm{Pa}^{\mathrm{n}} \\
\mathrm{n}=0.56\end{array}$ & $\begin{array}{l}\text { Ricketts (2014) [7] } \\
\text { Note: C and } \mathrm{n} \text { values are } \\
\text { average values. }\end{array}$ \\
\hline
\end{tabular}


Table 3. Inputs of mechanical systems for the CONTAM model.

\begin{tabular}{|c|c|c|}
\hline $\begin{array}{l}\text { Mechanical } \\
\text { System }\end{array}$ & CONTAM Input & Source \\
\hline Roof-Top MAU & \multirow{2}{*}{$\begin{array}{l}\text { Fan performance } \\
\text { curve }\end{array}$} & \multirow{3}{*}{$\begin{array}{l}\text { Mechanical } \\
\text { drawing of the } \\
\text { subject building. }\end{array}$} \\
\hline $\begin{array}{l}\text { Roof-Top Exhaust } \\
\text { Fan }\end{array}$ & & \\
\hline $\begin{array}{l}\text { Suite-Based } \\
\text { Exhaust Fan }\end{array}$ & $\begin{array}{l}\text { Simple air } \\
\text { handling unit }\end{array}$ & \\
\hline
\end{tabular}

The base case model was developed to include three modelled floor configurations, including: 1) underground parking level, 2) suite level with test suite (on the $2^{\text {nd }}$ and the $23^{\text {rd }}$ floor), and 3 ) suite level without test suite. To reduce the computational burden and model complexity, the six suites on each side of the corridor were modelled as a single "suite dummy zone". The modelling frameworks of these three floor types are presented in Fig. 1, Fig. 2, and Fig. 3, respectively. Symbols that are used in the CONTAM base model are presented in Fig. 3.b.

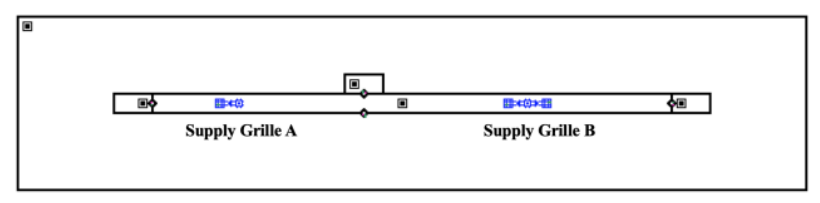

Fig. 1. CONTAM model framework of the underground parking level.

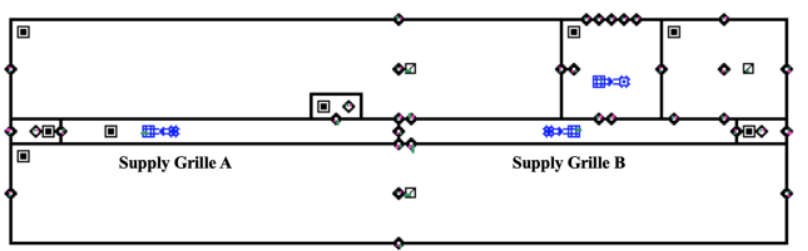

Fig. 2. CONTAM model framework of the suite level with test suite.

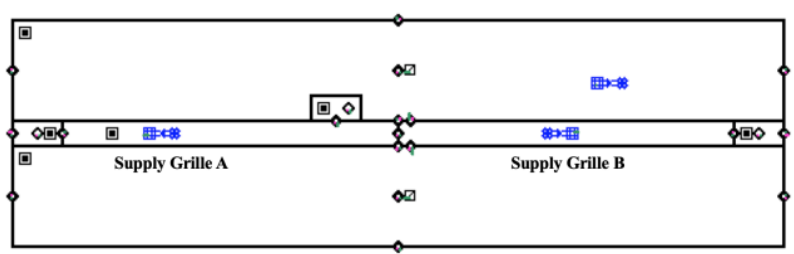

Fig. 3. CONTAM model framework of the suite level without test suite.

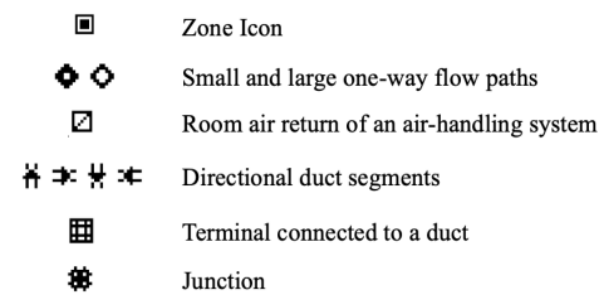

Fig. 3.b. Symbols used in the CONTAM base model.

\subsection{Model calibration}

This section presents the model calibration approach used for the base model (traditional pressurized corridor ventilation strategy), the direct-to-suite ducting ventilation system model, and the suite-based HRV ventilation system model.

\subsubsection{Base model calibration}

The rationale for the calibration procedure used in this study was based on the damper adjustment procedure when a MAU is commissioned. In practice, when a MAU is commissioned, a technician would walk through the building from top to bottom and adjust the damper position of each supply grille (represented by the terminal loss coefficient in the model) such that the airflow distributed from that grille matches its designed airflow rate. Although the damper adjustment procedure should be an iterative process given that the pressure loss distribution of the whole mechanical system changes after one terminal loss coefficient changes, the iterative process is labor and time intensive. Therefore, it is assumed that a single-pass damper adjustment process is more realistic and practical, and our consultation with industry supports this assumption. Therefore, the base model was calibrated using the following steps: 1) input the fan performance curve of the two roof-top MAUs, 2) input minor loss coefficients for all duct fittings in the building system, 3) input terminal loss coefficients for the supply grilles based on the size of the supply branch and the designed airflow on each level, and 4) moving through the building from top (24th floor) to bottom (sub-basement), adjust the terminal loss coefficients of each supply grille such that the airflow of that specific grille matches the designed airflow after adjustment. The damper position (i.e., the terminal loss coefficient) remained fixed after this single-pass adjustment.

Based on the mechanical drawings of the subject building, the design airflow rates were as follows:

- corridor supply to the $2^{\text {nd }}-24^{\text {th }}$ floor: $209 \mathrm{~L} / \mathrm{s}$ per grille with two supply grilles per floor;

- corridor supply for the $1^{\text {st }}$ floor: $147 \mathrm{~L} / \mathrm{s}$ per grille for two grilles;

- corridor supply of the basement and the subbasement: $132 \mathrm{~L} / \mathrm{s}$ for one grille and $226 \mathrm{~L} / \mathrm{s}$ for the other grille on each floor.

To validate this model calibration procedure, the simulation results of the airflow delivered by Supply Grille A and Supply Grille B of the base model in summer and in winter were compared to the field measurements of these airflows at the subject building. As part of this study, the airflow rate from the corridor supply grilles in the subject building were measured in both summer $\left[30^{\circ} \mathrm{C}\right]$ and winter $\left[2^{\circ} \mathrm{C}\right]$ using a Retrotec Flow Finder MK2 Powered Flow Hood, which has a measurement range of 10 to $850 \mathrm{~m}^{3} / \mathrm{h}$ and an air flow uncertainty of $3 \%$ of the reading [21]. For each supply grille on each floor, three measurements were taken and the average of these three measurements was used as the 
airflow rate for the corresponding grille. However, the supply airflows of the grills on the two underground parking floors were not measured during the field test. Therefore, to estimate the air flow rate for these grilles, the fraction of the design air flow rate for each measured grille was determined (i.e. measured airflow/design airflow). The average of these fractions was applied to the design air flow rate for the underground grilles to estimate the unmeasured airflows.

From the field measurements, the total airflow of all supply grilles connected to each MAU was determined. The resulting total airflow was then input as a constant volume flow for the modelled MAU, replacing the initial fan performance curve. The constant volume flow guaranteed that the total airflow supplied by each MAU was the same as that during the field test. The ambient temperature was set to be the same as that during the field test as well. Using this approach, a direct comparison could be made between the simulation results and the field measurements. The model validation results are presented in the following sections.

Lastly, given that the base case strategy relies on suite door undercuts to deliver ventilation air from the corridor to individual suites, the average $C$ and $n$ value of airtightness measurements of nine similar suite entrance doors in a study by Ricketts, with undercut heights ranging from 0 to $22 \mathrm{~mm}$ [7], were used. These values correspond to a "loose" door construction, from an air tightness perspective. Conversely, the direct-tosuite ducting strategy and suite-based HRV strategy do not rely on the door undercut for air delivery. Thus, the suite entrance door was modelled to be "tight", with a door undercut height of $6 \mathrm{~mm}$, for these two strategies. All other building input parameters stayed the same.

\subsubsection{Direct-to-suite ducting ventilation system model calibration}

The direct-to-suite ducting ventilation system model was calibrated using the same steps as the base model, except that the starting terminal loss coefficients were 3 (unitless), which is the fully-open loss coefficient.

For a direct comparison to the base model, the same roof-top MAUs were used in this model. The design airflow rate for each suite is $24 \mathrm{~L} / \mathrm{s}$ which is based on ASHRAE Standard 62.2 [4], assuming the area of individual suites is between 47 and $93 \mathrm{~m}^{2}$, with twobedrooms in total. The original design airflow rate for each grille on the $2^{\text {nd }}$ Floor to the $24^{\text {th }}$ Floor is $209 \mathrm{~L} / \mathrm{s}$, which is intended to supply six suites and half of the common corridor. Therefore, since the suites no longer needed to be ventilated by air from the corridor, the design airflow of the corridor supplies on the $2^{\text {nd }}$ floor to the $24^{\text {th }}$ floor were adjusted to $65 \mathrm{~L} / \mathrm{s}$ per grille (i.e. 209 $\mathrm{L} / \mathrm{s}-24 \mathrm{~L} / \mathrm{s} /$ suite $\times 6$ suites). Using the same approach, we found that $51 \mathrm{~L} / \mathrm{s}$ per grille was needed on the $1^{\text {st }}$ floor. The basement and the sub-basement used the same design airflow as the base model.

From the base case model calibration, we found that the minor losses of the duct fittings in the building system were very small compared to the terminal loss coefficients of the supply grilles. For example, after the base model was calibrated, the terminal losses of supply grilles were between 42 and 130 (unitless), while the minor losses of duct fittings were between 0 and 4 (unitless). Therefore, the minor losses of the duct fittings in the direct-to-suite ducting model were ignored.

\subsubsection{Suite-based HRV ventilation system model}

The suite-based HRVs were modeled by adding simple air handling units with a capacity of $24 \mathrm{~L} / \mathrm{s}$ per suite in the suite zones. A central pressurized corridor ventilation system was still required in this model to maintain positive corridor pressurization and prevent air transfer from one suite into another via the corridor. The vertical duct dimensions from the MAUs remained the same in this model, given the retrofit context. The design air flow rates used for the corridor grilles in this model were the same as the flow rates in the direct-to-suite ducting model. This smaller central system was calibrated using the same steps as the base case model, except that the starting terminal loss coefficients were 3 (unitless).

\section{Results and discussion}

This section begins by presenting the base case model validation results. Then, the corridor and suite ventilation airflow rates and the differential pressures between the corridor and suites in both summer and winter are compared for the three investigated systems.

\subsection{Base model validation results}

From the field measurements, the total airflow of MAU A, connected to Supply Grille A on each floor, was 2991 $\mathrm{L} / \mathrm{s}$ in summer and $3513 \mathrm{~L} / \mathrm{s}$ in winter. The total airflow of MAU B, connected to Supply Grille B on each floor, was $2648 \mathrm{~L} / \mathrm{s}$ in summer and $2699 \mathrm{~L} / \mathrm{s}$ in winter.

The minimum and the maximum measurements, together with the instrument error of $3 \%$ of the reading, were compared to the simulation results to validate the base model after calibration. The results are presented in Fig. 4 for Supply Grille A and Fig. 5 for Supply Grille B.

Fig. 4 shows that both the simulation results and the field measurements demonstrate that the supply airflow is higher on the top of the building and lower at the bottom of the building in both summer and winter for Supply Grille A. However, discrepancies between the simulation results and the field measurements were observed, and more so for Supply Grille B. We believe that the primary reason for this disagreement is that the actual damper positions of all supply grilles at the case study building during the field measurements were unknown. For example, Fig. 5 shows that Supply Grille $\mathrm{B}$ on the $24^{\text {th }}$ Floor had a much higher airflow compared to the rest of the building. Similarly, field measurements in Fig. 5 show that airflow decreases from the $1^{\text {st }}$ Floor to the $5^{\text {th }}$ Floor, which is opposite to the decreasing trend from top to bottom of the building. These trends may be an indication that some dampers might not have been 
adjusted properly when the MAU was commissioned or were adjusted after commissioning was complete.

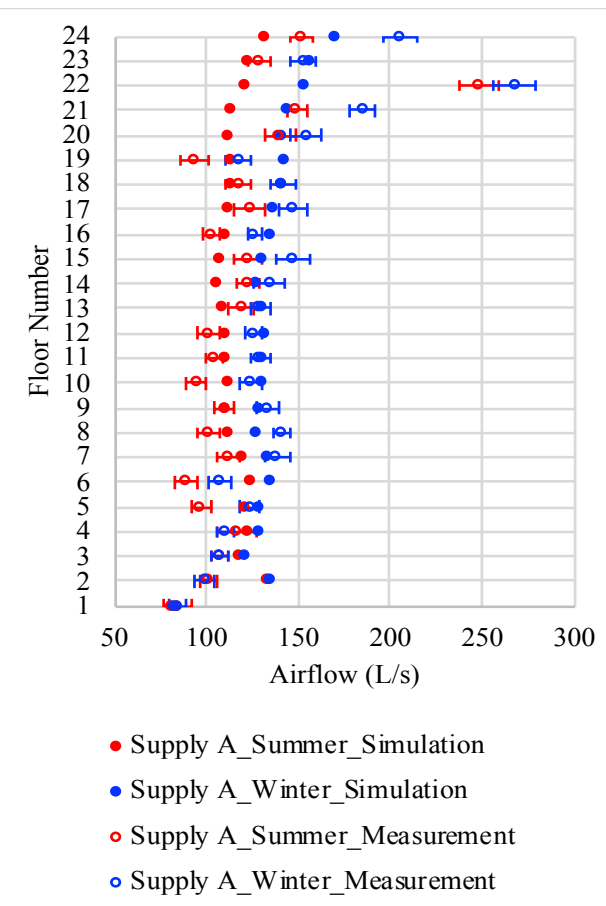

Fig. 4. Comparison of simulation results and field measurements of Supply Grille A in summer and winter.

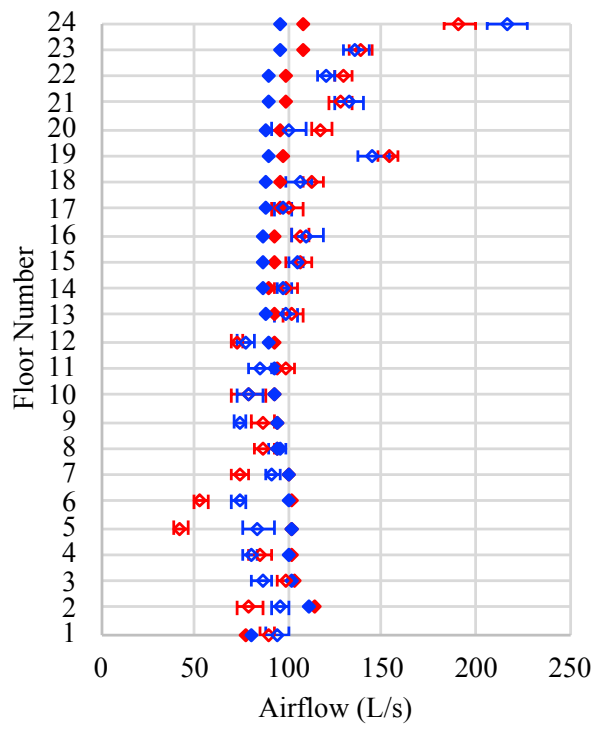

- Supply B_Summer_Simulation

- Supply B_Winter_Simulation

- Supply B_Summer_Measurement

$\diamond$ Supply B_Winter_Measurement

Fig. 5. Comparison of simulation results and field measurements of Supply Grille B in summer and winter.

In addition to the unknown damper positions, the fact that window operation and wind effects were not included as part of the model due to a lack of field data may have also contributed to the discrepancies between simulation results and field measurements.
Notwithstanding these discrepancies, given that during the retrofits the damper positions would be re-tuned, and because the base model is calibrated using the same approach as the retrofit models, this validation was deemed sufficient since the results from these two models are being used comparatively.

\subsection{Comparison of corridor supply airflow of the three ventilation strategies}

To compare the ventilation effectiveness of these three strategies, the total airflow of both MAUs in the base model and the direct-to-suite ducting model was set as a constant volume flow of $4955 \mathrm{~L} / \mathrm{s}$, which is the designed total airflow of the MAU in the subject building. In the suite-based HRV model, the MAU is only used to pressurize the corridors. Therefore, the two MAUs of the suite-based HRV model were set to be constant volume flows of $1810 \mathrm{~L} / \mathrm{s}$ and $1998 \mathrm{~L} / \mathrm{s}$, respectively. Airflow simulations were performed for the base model, the direct-to-suite ducting model, and the suite-based HRV model under both summer and winter conditions.

First, to investigate the ability of each ventilation strategy to overcome stack effect, the corridor supply airflows of Supply Grille A were determined for each ventilation strategy in both summer and winter. To determine the impact of stack effect, the difference between the supply airflow in summer and in winter on each floor was calculated for each ventilation strategy. The minimum, average, and maximum differences between the summer and winter airflow rates of each ventilation strategy for the building are presented in Table 4.

Table 4. Minimum, average, and maximum differences between the supply airflow rate in summer and winter for Supply Grille A under the three ventilation strategies.

\begin{tabular}{|l|l|l|l|}
\hline $\begin{array}{l}\text { Ventilation } \\
\text { Strategy }\end{array}$ & $\begin{array}{l}\text { Minimum } \\
\text { Difference } \\
(\mathbf{L} / \mathbf{s})\end{array}$ & $\begin{array}{l}\text { Average } \\
\text { Difference } \\
\text { (L/s) }\end{array}$ & $\begin{array}{l}\text { Maximum } \\
\text { Difference } \\
\text { (L/s) }\end{array}$ \\
\hline Base Case & 0.21 & 3.85 & 12.60 \\
\hline $\begin{array}{l}\text { Direct-to- } \\
\text { Suite Ducted }\end{array}$ & 0.01 & 1.08 & 3.19 \\
\hline $\begin{array}{l}\text { Suite-Based } \\
\text { HRV }\end{array}$ & 0.01 & 0.38 & 0.98 \\
\hline
\end{tabular}

Table 4 shows that the airflow rate delivered by Supply Grille A varies the most between summer and winter for the base case model. There still is a seasonal variation in supply airflows for the direct-to-suite ducted strategy, but it is less than the base case model. The supply airflow throughout the building is the most consistent for the suite-based HRV strategy under the seasonal differences.

\subsection{Comparison of airflow delivered to test suites of the three ventilation strategies}

To further analyze the impacts of stack effect on airflow delivered to individual suites in summer and winter, the ventilation airflow rate delivered to two test suites, located at the $2^{\text {nd }}$ Floor and the $23^{\text {rd }}$ Floor, of the base 
model and the direct-to-suite ducted model, are presented in Fig. 6. Given that the suite-based HRV model utilizes a constant supply of $24 \mathrm{~L} / \mathrm{s}$ in each suite as a model input, the ventilation airflow rate under this strategy could not vary seasonally.

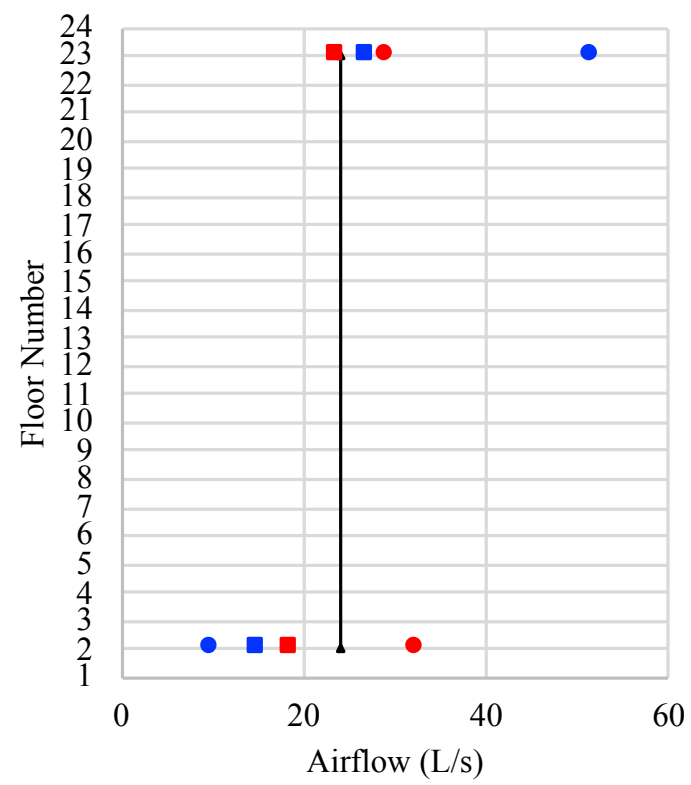

- Base_Summer

- Base_Winter

- Direct-to-Suite_Summer

- Direct-to-Suite_Winter

$\longrightarrow$ ASHRAE 62.2 Requirement (and HRV)

Fig. 6. Comparison of ventilation air delivered to test suites of the base model, the direct-to-suite ducted model, and the suitebased HRV model under summer and winter conditions.

For both systems, Fig. 6 shows that the airflow rate delivered to the test suite located on the $2^{\text {nd }}$ Floor tends to be lower than that delivered to the test suite located on the $23^{\text {rd }}$ Floor, especially in winter. This uneven distribution of ventilation air throughout the building is expected. Given that the ventilation air is delivered by the roof-top MAU, the airflow decreases when moving from the top to the bottom of the building, causing under-ventilation and over-ventilation in different parts of the building. Moreover, in winter, stack effect impacts the airflow distribution as the warm air rises to the top of the building, creating a low-pressure region at the bottom of the building and a higher pressure region at the top.

When comparing the base model and the direct-tosuite ducted ventilation system, Fig. 6 shows that the impact of the roof-top MAU location and stack effect are less pronounced in the direct-to-suite ducted model. This is because the base model relies on door undercuts to deliver air into suites while the direct-to-suite ducted model relies on ductwork directly reaching into individual suites to deliver the outdoor air. As a result, in the base model the majority of the ventilation air delivered by the corridor supply grille leaks into other airflow paths with lower resistance, such as the elevator shafts, and the stairwell. Conversely, in the direct-tosuite ducted model, airflow was delivered to both the corridor and the suites, leading to more effective suite ventilation.

Although the direct-to-suite ducting strategy can deliver more evenly distributed airflow to the whole building, it is unable to overcome stack effect in winter. Therefore, a decentralized ventilation system such as the suite-based HRV strategy may the better choice to avoid over-ventilation and under-ventilation issues.

\subsection{Comparison of corridor pressure differential relative to surrounding suites of the three ventilation strategies}

All three ventilation strategies require positive pressurization of the common corridor to prevent intersuite migration of odors and contaminants. To investigate whether these three systems are able to maintain corridor pressurization in a high-rise building, the pressure differential of the corridor relative to surrounding suites was simulated and the results are presented in Fig. 7 for summer and Fig. 8 for winter.

The results show that all three strategies are able to maintain a positively pressurized corridor in summer but are unable to main a positively pressurized corridor at the bottom of the building in winter. As such, additional measures to improve corridor pressurization performance is needed for all systems.

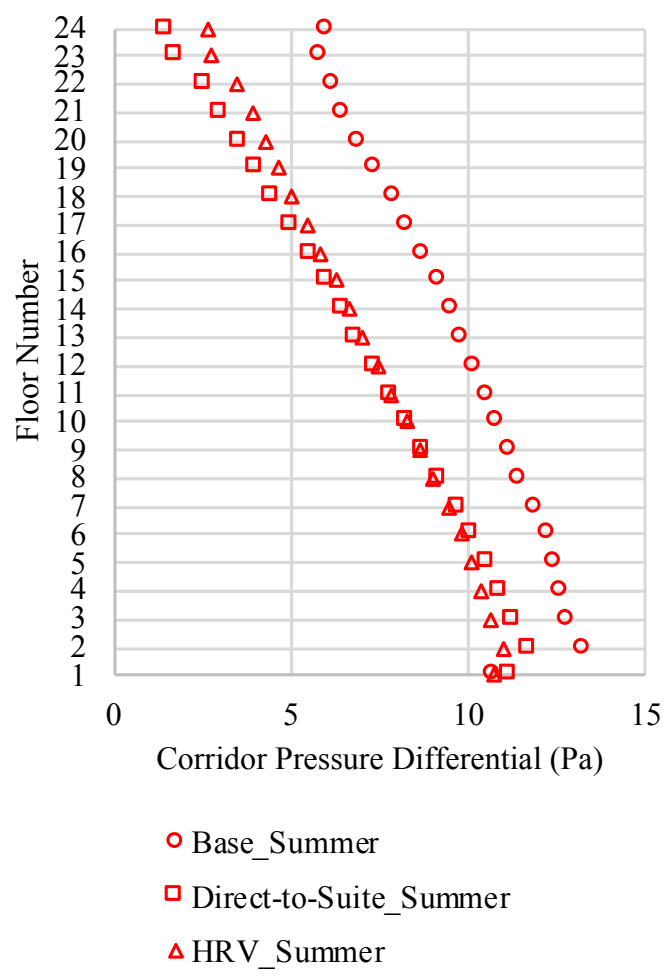

Fig. 7. Comparison of corridor pressure differential relative to surrounding suites simulation results of three ventilation strategies in summer. 


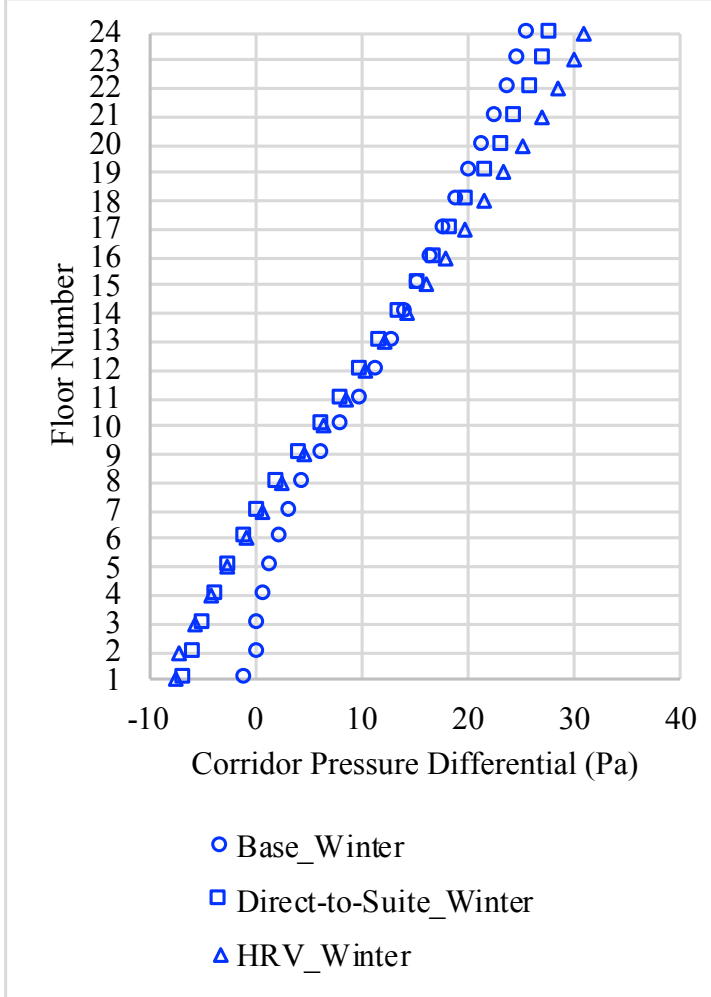

Fig. 8. Comparison of corridor pressure differential relative to surrounding suites simulation results of three ventilation strategies in winter.

\subsection{Limitations}

There were a number of limitations to this study. First, the sample size of the airtightness measurements obtained from field tests at the subject building is small. Moreover, the theoretical airtightness data obtained from the literature might not be representative of the subject building. In addition, it is challenging to account for all possible air leakage paths in a building. Therefore, only major leakage paths were included in the three models. Last, but not least, the wind effects and the impacts of window operations were not included in the models. For the purpose of the parametric evaluation presented here, the scope of this study was considered to be adequate.

\section{Conclusions and future research recommendations}

Using airtightness test data, a base model of a subject building in Toronto, Canada, was constructed in CONTAM. Three ventilation strategies were analyzed using this model, including the base strategy (pressurized corridor ventilation system), the direct-to-suite ducted ventilation strategy, and the decentralized suite-based HRV ventilation strategy. By comparing the airflow rates delivered to the corridor and to the test suites, as well as the corridor pressure differential relative to surrounding suites in both summer and winter, the simulation results show that the base model was impacted by the stack effect most significantly of the tested models in winter, causing an uneven distribution of ventilation air throughout the building. The direct-tosuite ducted strategy is more resistant to stack effect in different seasons. However, the issues of overventilation and under-ventilation still persist, which may not make it a retrofit strategy worth undertaking. The decentralized ventilation strategy, which uses suite-based HRVs combined with a pressurized corridor ventilation system, is able to provide consistent airflow to individual suites throughout the building in both seasons. These findings are in agreement with those found by CMHC (2003) [12], which conclude that decentralized systems are less susceptible to stack effects compared to centralized systems.

Future research recommendations include comparing these three ventilation strategies through case studies in real buildings. In addition, the impacts of other factors such as wind effect and window operations on system performance should be investigated.

\section{References}

1. J. Sundell, Indoor Air 14 (S7), 51-58 (2004)

2. D. P. Wyon, Indoor Air 14 (7), 92-101 (2004)

3. J. A. Leech, W. C. Nelson, R. T Burnett, S. Aaron, M. E. Raizenne, J. Expo. Sci. Environ. Epidemiol. 12, 427 (2002)

4. ASHRAE, ASHRAE Standard 62.2-2016 (2016)

5. P. Moffatt, I. Theaker, C. P. Wray, CMHC (1998)

6. K. Ueno, J. Lstiburek, D. Bergey, NREL, (No. DOE/GO-102012-3762, 2012)

7. L. Ricketts, http://hdl.handle.net/10012/8190 (2014)

8. G. Cooke, CMHC (2005)

9. J. W. Lstiburek, ASHRAE Journal 47 (12), 30 (2005)

10. D. L. Bohac, J. E. Fitzgerald, M. J. Hewett, D. Grimsrud, Proc. Buildings X: Thermal Performance of the Exterior Envelopes of Whole Buildings (2007)

11. S. Berkel, PhD diss. (2014)

12. CMHC, Technical Series 03-121 (2003)

13. M. Carlsson, MASc diss. (2017)

14. V. Murgul, D. Vuksanovic, N. Vatin, V. Pukhkal, Appl. Mech. Mater., Vol. 680, 524-528 (2014)

15. M. Saari, J. Laine, S. Karjalainen, K. Hamström, Proceedings of Healthy Buildings Vol. 2, 675 (2000)

16. T. A. Koiv, A. Mikola, R. Simson, Engineering, 7 (03), 129 (2015)

17. W. S. Dols, B. J. Polidoro, (No. Technical Note (NIST TN)-1887, 2015)

18. M. Orme, W. Liddament, A. Wilson, Coventry, Great Britain: AIVC (1998)

19. ASHRAE, ASHRAE Standard 90.1-2016 (2016)

20. C. Y. Shaw, J. T. Reardon, M. N. Said, R. J. Magee, Proceedings, 12th AIVC Conference, Ottawa, 359374 (1991)

21. Retrotec, https://retrotec.com/flow-finder-mk2.html (2020) 